\title{
Fast response cavity enhanced ozone monitor
}

\author{
A. L. Gomez and E. P. Rosen \\ Southwest Sciences, Inc. 1570 Pacheco St. Ste. E-11, Santa Fe, NM, USA \\ Correspondence to: A. L. Gomez (algomez@swsciences.com)
}

Received: 6 September 2012 - Published in Atmos. Meas. Tech. Discuss.: 26 September 2012

Revised: 1 February 2013 - Accepted: 4 February 2013 - Published: 27 February 2013

\begin{abstract}
Ozone is an important atmospheric gas due to its role in air quality and radiative forcing. A new method for sensitive, rapid monitoring of ambient ozone has been developed using a compact platform and relatively inexpensive components. Based on incoherent broadband cavity enhanced absorption spectroscopy (IBB-CEAS), the device utilizes an optical cavity of just $14.5 \mathrm{~cm}$ and $99.3 \%$ reflective mirrors. Performance of the instrument has been validated against direct absorption measurements in a single-pass measurement cell. Currently, the IBB-CEAS ozone instrument can achieve $\sim 1 \mathrm{ppb}$ sensitivities at $0.1 \mathrm{~s}$ integration time with a dynamic range over four orders of magnitude, accessing relevant ozone concentrations in both the stratosphere and troposphere. This new device offers improved sensitivity and time response for mapping ozone aboard airborne platforms.
\end{abstract}

\section{Introduction}

Environmental monitoring of ozone is vital due to the profound impact ozone has throughout the atmosphere. In the stratosphere, ozone strongly absorbs solar UV radiation that would otherwise be harmful to life on Earth (Cullen and Neale, 1994). Its presence in the troposphere influences radiative forcing (Gauss et al., 2003), gas phase photochemistry (Sillman, 1999; Finlayson-Pitts and Pitts, 1997), and can detrimentally impact the health of flora (Fuhrer and Booker, 2003), fauna, and humans (Gauderman et al., 2002).

Ozone's widely varying ambient mixing ratios, which range from parts per billion to parts per million, and its reactivity impose constraints on the sensitivity, dynamic range, and response rate necessary for an instrument making in situ measurements. These constraints are compounded for instruments aboard airborne platforms, where additional limitations on instrument sampling rate, weight, power, and size exist. At typical research aircraft speeds of $100-200 \mathrm{~m} \mathrm{~s}^{-1}$, such as those attained by NASA's P3, sampling rates are ideally greater than $1 \mathrm{~Hz}$ to achieve spatial resolution at the scale of mixing. High-resolution in situ measurements of ozone made from airborne platforms are essential for capturing eddy fluxes (Matross et al., 2006), characterizing plume dynamics (Brown et al., 2012; Jones et al., 2005), refining regional and global chemical models (Taghavi et al., 2005; Monks et al., 2009), and validating satellite retrievals (Liu and Tian, 2010). Additionally, such measurements can be beneficial for accurately quantifying other atmospheric species (Washenfelder et al., 2011).

In this paper we describe the development of a new instrument for monitoring ambient ozone that is specifically designed for compatibility with airborne research platforms. The instrument is based on ultraviolet absorption, which has been routinely applied for airborne ozone detection (Proffitt and McLaughlin, 1983; Gao et al., 2012; Kalnajs and Avallone, 2009) given ozone's large absorption cross-section of $1.15 \times 10^{-17} \mathrm{~cm}^{2} \mathrm{molec}^{-1}$ at $254 \mathrm{~nm}$ (Molina and Molina, 1986). This technique has key advantages for long duration, remote measurement of ozone over common alternatives such as electrochemistry (Komhyr, 1969) or chemiluminescence (Ridley et al., 1992; Zahn et al., 2012). Namely, it offers an absolute measurement of ozone without requiring consumables for calibration and operation.

One shortcoming with traditional UV absorption methods that we have sought to overcome is the tradeoff between instrument sensitivity and form factor. Absorption sensitivity is proportional to optical path length, as defined by the BeerLambert law. UV photometers relying on direct absorption (Kalnajs and Avallone, 2009) or a singly folded path (Proffitt and McLaughlin, 1983; Gao et al., 2012) have physical lengths on the order of the total optical path length, which can limit sampling rate due to the time required to completely 
exchange the volume of the sample cell. Resonant optical cavities can overcome limitations of direct absorbance measurements, reducing the physical size of an instrument while maintaining the long optical paths requisite for high sensitivity measurements. Here, we apply incoherent broadband cavity enhancement absorption spectroscopy (IBB-CEAS) to sensitively and rapidly detect ozone.

First developed by Fiedler et al. (2003), IBB-CEAS takes advantage of spectrally broad light to overlap hundreds to thousands of resonant cavity modes and generate a continuous transmission signal having an enhanced absorption response characteristic of a much longer physical pathlength (Fiedler et al., 2003). The approach has been used to make sensitive measurements on a variety of trace atmospheric gases (Venables et al., 2005; Gherman et al., 2008; Wu et al., 2008). A variant of cavity ring-down spectroscopy, which itself has been implemented recently for detection of ozone (Washenfelder et al., 2011), IBB-CEAS is less alignmentsensitive and can be implemented with simple electronics. As a continuous-wave technique, it also has far less stringent requirements than cavity ring-down regarding the light source used. Low-cost light emitting diodes have been demonstrated with IBB-CEAS (Ball et al., 2004; Langridge et al., 2006). With the emergence of solid state technology to produce LEDs operating at UV wavelengths relevant to ozone detection, LED-based UV photometers (Kalnajs and Avallone, 2009) are emerging as a useful alternative to instruments based on much more power-hungry mercury lamps (Proffitt and McLaughlin, 1983; Gao et al., 2012).

We present results from an LED-based IBB-CEAS UV photometer, which we believe to be the first application of the approach to measuring ozone. As detailed in the following sections, its compact $14.5 \mathrm{~cm}$ optical measurement cell is capable of yielding IBB-CEAS ozone measurements of $\sim 1 \mathrm{ppb}$ sensitivity at $0.1 \mathrm{~s}$, which compares very favorably to recent CEAS measurements of ozone obtained using an atomic line source (Darby et al., 2012).

\section{Experimental}

\subsection{Principle of operation}

The transmission intensity $(I)$ of light through an optical cavity, consisting of mirrors with reflectivity $R$, can be described (Fiedler et al., 2003) as the superposition of the sum of discrete transmitted light per pass. Transmission losses arise from the mirrors $(1-R)$ and from absorption loss, where $L$ is the single-pass loss. The observed transmission intensity is related to the intensity of light into the cavity, $I_{\text {in }}$, according to

$$
I=I_{\text {in }} \frac{(1-R)^{2}(1-L)}{1-R^{2}(1-L)^{2}} .
$$

For an unloaded cavity $(L=0)$, this reduces to

$I_{\mathrm{o}}=I_{\mathrm{in}} \frac{(1-R)}{(1+R)}$.

Hence, the cavity transmission $(T)$ is

$T=\frac{I}{I_{\mathrm{o}}}=\frac{1-R^{2}}{1-R^{2}(1-L)^{2}}$.

The measured cavity enhancement gained from using a resonant cell versus a single-pass cell can be expressed as the ratio of the resonant transmission loss to the single-pass loss:

$E=\frac{1-I / I_{\mathrm{O}}}{L}$,

and the maximum theoretical enhancement is given by

$E=\frac{1}{(1-R)}$.

Conveniently, the enhancement gains are greatest when the loss is the smallest. This low loss enhancement is what allows exceptional sensitivity in a compact absorption cavity.

\subsection{Technical design}

The IBB-CEAS system consists of the following: (1) UV source/detection; (2) measurement cells (resonant and single-pass reference); (3) flow handling; (4) ozone generation/neutralization; and (5) data acquisition. The instrument was built upon the Thorlabs $30 \mathrm{~mm}$ cagemount system to facilitate breadboard design and provide ruggedness. The measurement portion of the system (except current driver and amplifier) was housed in a polystyrene foam enclosure for thermal stability. A rendering and optical layout of the system can be seen in Fig. 1. As a proof-of-principle benchtop system, using off-the-shelf optomechanics, the optical measurement system had dimensions of $17^{\prime \prime} \times 4.75^{\prime \prime} \times 2.5^{\prime \prime}$. A ruggedized, field-ready instrument based on this technology could be expected to have a footprint of $13.5^{\prime \prime} \times 3^{\prime \prime} \times 2^{\prime \prime}$ for the optical system, and a total instrument size on the order of $15^{\prime \prime} \times 6^{\prime \prime} \times 4^{\prime \prime}$.

\subsection{Optical design}

Light from a UV LED was imaged with an $f=35 \mathrm{~mm}$ fused silica aspheric lens and apertured with a pair of irises separated by $\sim 5 \mathrm{~cm}$ to generate a nearly collimated $\sim 3 \mathrm{~mm}$ diameter beam of light. A UV bandpass filter (Semrock: 252 $268 \mathrm{~nm}$, Fig. 2) removed most unwanted emission from the LED, and the resulting filtered light was split with a $70 \mathrm{~T} / 30 \mathrm{R}$ thin plate dielectric beam splitter (NewFocus). The $70 \%$ transmitted portion of the UV light passed through the IBB-CEAS measurement cell and was imaged onto a detector with an $f=25 \mathrm{~mm}$ fused silica spherical lens. The IBBCEAS cell was formed with a pair of $1 / 4^{\prime \prime}$ thick fused silica 


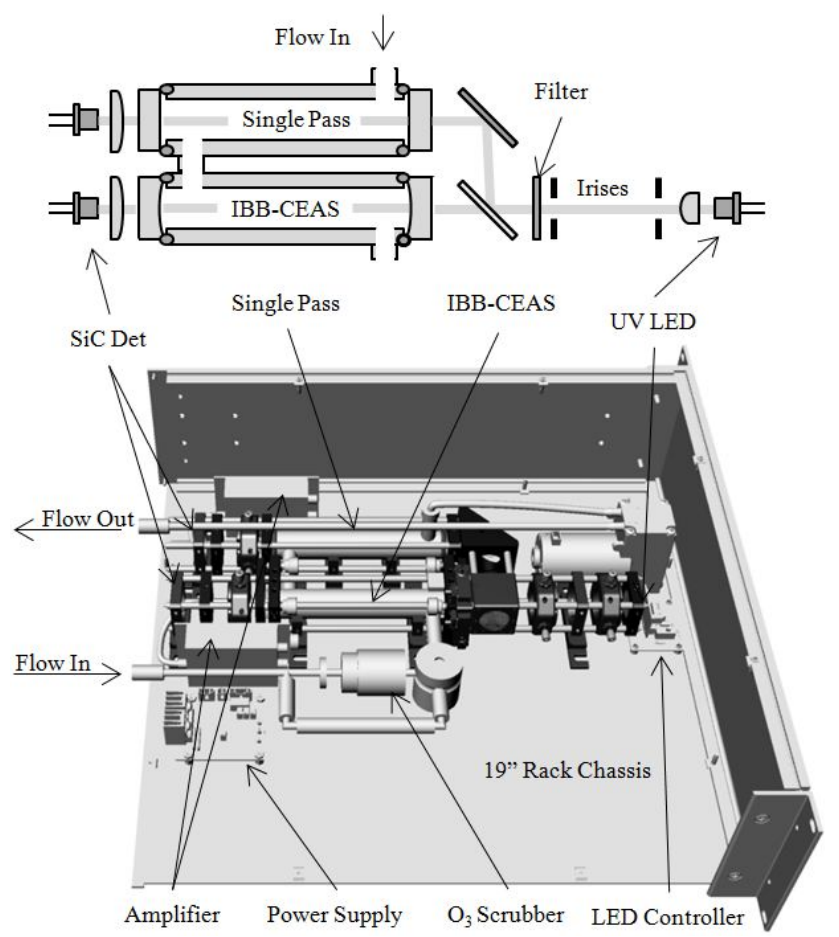

Fig. 1. Optical layout (top) and rendering (bottom) of simultaneous IBB-CEAS and single-pass ozone measurement system in a standard $19^{\prime \prime}$ rackmount chassis.

concave mirrors $(f=-150 \mathrm{~mm})$ having a $99.3 \%$ dielectric coating on the concave surface and anti-reflection coating on the plano surface. The mirrors were separated by $14.5 \mathrm{~cm}$ to form a stable $\left(0 \leq g_{1} \cdot g_{2}=0.87 \leq 1\right)$ resonator (Busch et al., 1999).

The $30 \%$ reflected portion was directed by a UV turning mirror (CVI: Maxbrite 245-390 nm) through a single-pass measurement cell and imaged onto a silicon carbide detector with an $f=25 \mathrm{~mm}$ fused silica spherical lens. The singlepass cell had a path length of $14.5 \mathrm{~cm}$ matching the physical length of the IBB-CEAS cell, and used UV-AR coated fused silica windows. This dual cell design allowed for simultaneous calibration and quantification of cavity enhancement, and extended the dynamic range of ozone measurements made by the instrument.

\subsection{UV source}

UV light was generated by a UV-Top LED (peak $=254.5 \mathrm{~nm}$, FWHM $=11.1 \mathrm{~nm}$ ) mounted into a cagemount LED adaptor. The LED was driven by an ILX current driver at $20 \mathrm{~mA}$ producing $\sim 300 \mu \mathrm{W}$ of available optical power. This LED has a temperature-dependent drift of $\sim 1.5 \% \mathrm{~K}^{-1}$ at $20 \mathrm{~mA}$, which necessitates temperature stability measures. A high thermal mass holder, coupled with insulation, is sufficient for laboratory work. A field instrument may require an additional monitoring photodiode to maintain performance.

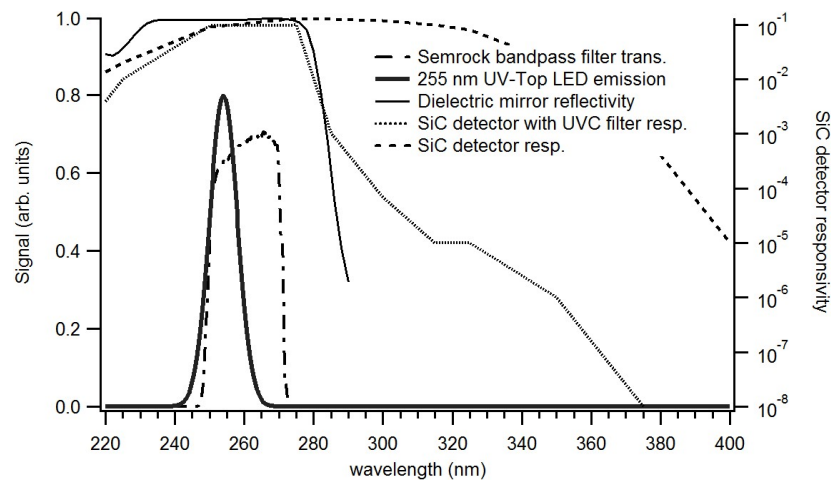

Fig. 2. Wavelength dependence of components in the system.

\subsection{Detection and data acquisition}

Silicon carbide photodiodes (Electro Optical Components: JEC 1.6RC with integrated UV-C filter, $1.6 \mathrm{~mm}^{2}$ ) were used for both single-pass and IBB-CEAS measurement channels. Photodiodes were mounted into $1^{\prime \prime}$ OD machined aluminum cylinders and soldered to $12^{\prime \prime}$ lengths of BNCterminated, shielded coax cables. The detectors were amplified by Stanford Research Systems SRS-570 low noise current amplifiers. IBB-CEAS and single-pass channels were set to $100 \mathrm{pA} \mathrm{V}^{-1}$ and $50 \mathrm{nA} \mathrm{V}^{-1}$ gain respectively, low-pass filtered at $100 \mathrm{~Hz}$, and operated in low drift mode. The resulting signal ranged from 1 to $1.6 \mathrm{~V}$, such that even though most of the LED emission is rejected by the aperture pair and input cavity mirror, sufficient light reaches the detector to make sensitive measurements at high signal-to-noise.

The amplified detector signals were acquired using a $\mathrm{Na}-$ tional Instruments DAQ multi-function I/O card (NI USB$6251 \mathrm{BNC}$ ) and recorded using a custom Labview VI. Data were acquired at 10000 points/sample at $\pm 2 \mathrm{~V}$ full scale at 16 bit.

\subsection{Sample cell}

To minimize ozone loss within the instrument, the sample cells were made out of virgin PTFE Teflon. 1" OD rods were machined to $14.5 \mathrm{~cm}$ in length and bored out to $5 / 8^{\prime \prime}$ inner diameter. Both ends were machined to accept recessed Viton fluoropolymer O-rings for compression seals with optics. NPT ports were machined into the ends and were fitted with NPT-Swagelok Teflon fittings for gas flow.

\subsection{Flow handling}

The IBB-CEAS cell and the single-pass cell were plumbed in series with Teflon tubing such that both cells measured the same sample gases, which were drawn through the system using a diaphragm pump. Flow was regulated with a Swagelok ball valve and monitored on a Matheson flow 

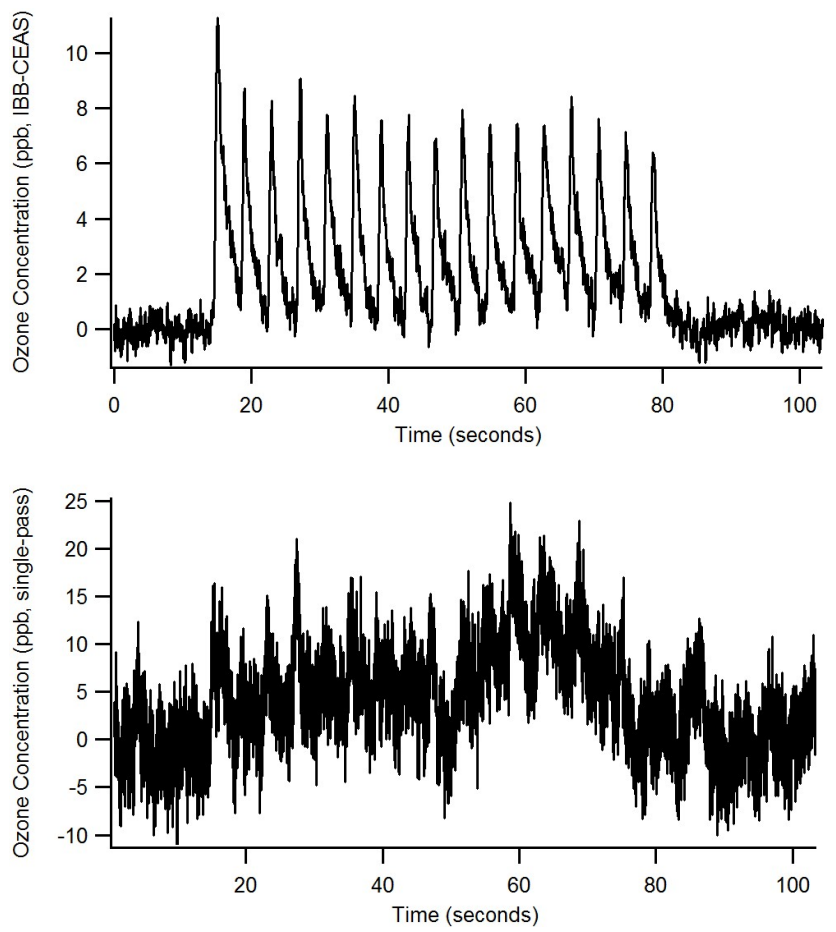

Fig. 3. Simultaneous IBB-CEAS (top) and single-pass (bottom) transmission measurements taken at $0.01 \mathrm{~s}$ integration, of periodic ozone concentration spikes generated from discrete $\mathrm{Hg}$ lamp pulses.

gauge to be $\sim 500 \mathrm{cc} \mathrm{s}^{-1}$. All fittings and tubing were pure Teflon up to the exit of the final measurement cell.

\subsection{Ozone generation and scrubber}

Ozone was generated by flowing unfiltered laboratory air through a lab-built aluminum reaction cell containing a nearly continuous (fast pulse) mercury vapor lamp (Oriel). The photolysis of $\mathrm{O}_{2}$ in air by lamp generated $183 \mathrm{~nm}$ light from the lamp, which produced sufficient quantities of ozone to evaluate instrument performance. Concentrations of ozone within the reaction cell could be varied by altering the discharge current to the lamp, and ratios could be further adjusted by mixing ozone-laden air with lab air. This was necessary for generating low ozone concentrations, since the $\mathrm{Hg}$ lamp pulse became resolvable at low currents (Fig. 3). When applicable, ozone was neutralized with an in-line canister containing $\sim 130 \mathrm{~cm}^{3}$ of high surface area granular carbon to evaluate $I_{0}$. For demonstration purposes, the selection of activated carbon was entirely sufficient to completely neutralize all ozone present. We anticipate that a field instrument would employ $\mathrm{MnO}_{2}$ for this purpose in order to ensure that any potential UV-absorbing organic interferents were not removed from the process stream causing measurement bias (Zucco et al., 2003; Viallon et al., 2006). Additionally, it is expected that a field-deployed device would also require a Teflon particulate filter.

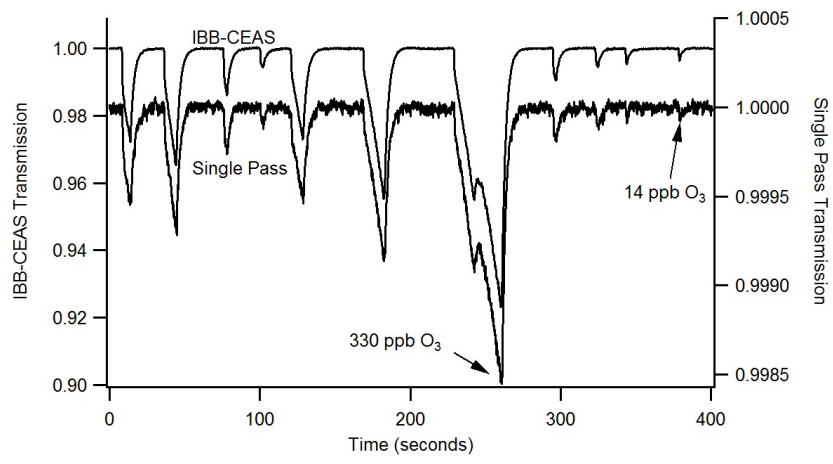

Fig. 4. Simultaneous $0.1 \mathrm{~s}$ integration IBB-CEAS and single-pass transmission measurements of periodic ozone introductions.

\section{Results}

The performance capability for measuring ozone with the IBB-CEAS technique was evaluated through direct comparison with a matching single-pass absorption measurement. Side-by-side comparisons with other instruments were beyond the scope of the project. The ozone reservoir was periodically sampled into the coupled IBB-CEAS and singlepass cells at various mixing ratios with ambient air to obtain a wide range of measured concentrations. Figure 4 shows the results from sampling bursts of ozone-laden air into the sample cells, illustrating the improvement in the signal-tonoise of the IBB-CEAS measurement over the single-pass measurement. For the lowest concentration of measurements $(0.1 \mathrm{~s}$ integration), the single-pass measurements barely discern an ozone signal, while the IBB-CEAS measurements clearly show a transience in ozone concentration.

Comparison of the measured transmission losses between the cavity-enhanced cell and single-pass cell allows the enhancement gain from the IBB-CEAS measurement cell to be determined according to Eq. (4). These results, corrected for $I_{\mathrm{O}}$ drift, are shown in Fig. 5. An enhancement factor of 50fold is clearly shown for the IBB-CEAS measurement with respect to the single-pass measurement. Scatter at low loss is due to noise in the single-pass measurements used in the calculation. The observed transmission loss in the single-pass and IBB-CEAS cell can be directly converted to an ozone concentration by applying Eq. (6):

$c=\frac{-\ln \left(\frac{I}{I_{\mathrm{o}}}\right)}{E \cdot \alpha \cdot L \cdot X \cdot \frac{P_{\mathrm{o}}}{P}}$,

where $E$ is the enhancement factor, $\alpha$ is the absorption cross section, $X$ is the molecular density of air at 760 Torr and $P$ is the measurement pressure relative to 760 Torr $\left(P_{\mathrm{o}}\right)$. For this calculation, we use an effective cross section of $1.04 \times 10^{-17} \mathrm{~cm}^{2} \mathrm{molec}^{-1}$, which is the ozone cross section weighted by the emission of the LED and bandpass of the filter (Fig. 2). A constant value of $I_{\mathrm{O}}$ is used and was obtained before each experiment by using lab air exclusively 


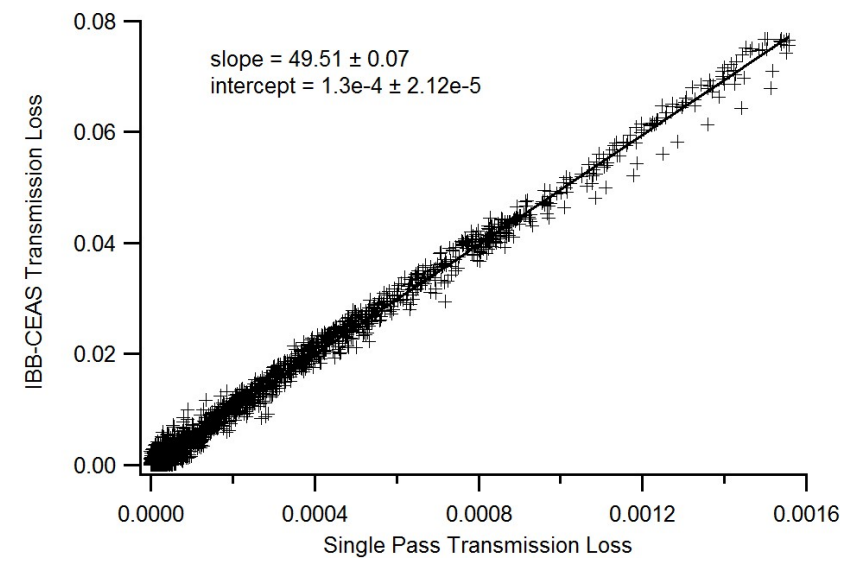

Fig. 5. Measured transmission losses for IBB-CEAS vs. single-pass sample cells with matching ozone concentrations, indicating an enhancement value of $50 \times$. Scatter is due to noise in the single-pass measurements used in the calculation (see Fig. 4).

or passing ozone-laden air through a neutralizer (continuous measurements of $I$ with neutralizer in line for ozone off and ozone generation at maximum show no change, indicating complete neutralization).

In Fig. 4, the IBB-CEAS system demonstrates measurements from $330 \mathrm{ppb}$ to $14 \mathrm{ppb}$ with a standard deviation noise floor of $<1 \mathrm{ppb}$ ozone. These data, taken at $0.1 \mathrm{~s}$ integration time, also demonstrated the minimal averaging time required to achieve high sensitivity. Lower ozone mixing ratios were explored by operating the ozone lamp at low current. Under this regime, the lamp transitions from quasi-continuous (very rapid pulses) to pulsed emission. When the current on the lamp's power supply output is adjusted to the lowest setting, the lamp undergoes periodic capacitive discharge, generating discrete bursts of light and ozone approximately every $4 \mathrm{~s}$. Figure 3 demonstrates the detection of transient, low concentration ozone levels generated from the lamp flashes. These data, acquired at $100 \mathrm{~Hz}$, show that IBB-CEAS is vastly superior to the single-pass measurement, fully resolving the $<10 \mathrm{ppb}$ ozone bursts with a limit of detection of $\sim 1 \mathrm{ppb}$.

System stability, shown in Fig. 6, was determined from Allan variance analysis (Werle, 2011). Data were acquired for $6000 \mathrm{~s}$ for both the amplifier (DC, LED off) and the stabilized cavity throughput $\left(I_{0}\right.$, LED on) at $0.1 \mathrm{~s}$ integration time. Effective concentration for the amplifier + detector noise (LED off) was calculated by scaling the signal by $I_{\mathrm{o}}$ (LED on), offsetting such that the mean of $I_{\mathrm{DC}}=1$, and then performing Allan calculations. The variance was calculated for data binned from 0.1 to $600 \mathrm{~s}$ of data averaging. Over the course of acquisition, the DC component from the amplifier was stable and showed no substantial long-term drift. The $I_{\mathrm{O}}$ component of the system, which includes the DC component plus LED output stability and cavity coupling stability, had drift of $\pm 0.2 \%$ over $100 \mathrm{~min}$. The system stability is well below an effective $1 \mathrm{ppb}$ ozone concentration at

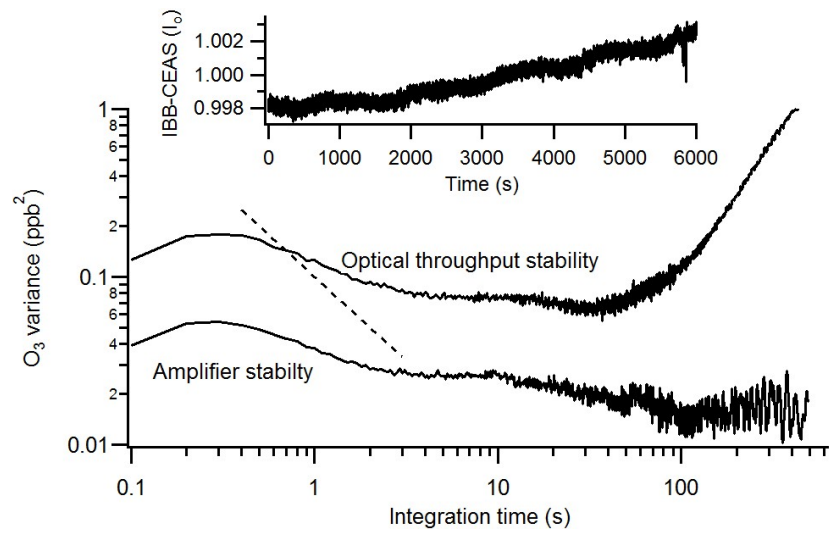

Fig. 6. Allan variance analysis to determine improvement gains from data averaging, and the time domain for re-zeroing of the background to attain a targeted precision. Dashed line represents theoretical white noise. Roll off at $0.1-0.4 \mathrm{~s}$ integration is related to amplifier bandwidth limit.

$10 \mathrm{~Hz}$, and only exceeds this threshold after approximately $400 \mathrm{~s}$ of integration.

\section{Discussion}

According to Eq. (5), the theoretical enhancement for a cavity consisting of mirrors with $R=99.3 \%$ should approach a factor of 142 as cavity losses decrease. The data presented in Fig. 5 indicate that, for small losses, the IBB-CEAS system has a measured enhancement of approximately 50 with respect to a single-pass cell. This difference in enhancement may arise from one or a combination of the following sources: (1) cavity coupling; (2) Rayleigh scattering; and/or (3) out of band light (OBL). Each of these sources was evaluated systematically. Cavity coupling was investigated by changing the input conditions of the LED by varying the focal plane of the mode matching optics and by aperturing incident emission, neither of which provided a significant improvement on enhancement. Rayleigh scattering was calculated to be an insignificant loss term compared to the cavity loss at $255 \mathrm{~nm}\left(4 \times 10^{-5}\right)$ and was verified with low pressure experiments. OBL, however, appears to explain the enhancement discrepancy. OBL is simply light generated from the LED measured by the photodetector that falls outside the mirror reflectivity band, such that it has a considerably shorter effective path length through the cell than in band light. Since it is non-resonant (or lower resonant for light that sits on the shoulder of the reflectivity curve), OBL suppresses enhancement when it is averaged with the transmitted signal. We tested the effect of reducing OBL by comparing two $\mathrm{SiC}$ detectors, where one had a UV-C $(220-275 \mathrm{~nm})$ filter integrated in the package housing. Although the UV-C filter is not optimized to remove all OBL from the LED, this simple modification improved the enhancement from $\sim 30 \times$ to $50 \times$. 
Table 1. Performance comparison of ozone instruments.

\begin{tabular}{llrrrl}
\hline & Method & $\begin{array}{l}\text { Physical } \\
\text { length } \\
(\mathrm{cm})\end{array}$ & $\begin{array}{l}\text { Sensiti- } \\
\text { vity } \\
(\mathrm{ppb})\end{array}$ & $\begin{array}{l}\text { Response } \\
\text { Rate } \\
(\mathrm{Hz})\end{array}$ & $\begin{array}{l}\text { Special } \\
\text { Considerations }\end{array}$ \\
\hline This work & IBB-CEAS & 14.5 & $<1$ & 10 & UV LED temperature dependence \\
2B Technologies Model 205 & UV absorption & 15 & 3 & 0.1 & Long averaging for high sensitivity \\
Kalnajs (2009) & UV absorption & 50 & 1 & 1 & UV LED temperature dependence \\
Gao (2012) & UV absorption & 30 & 0.4 & 2 & High power usage \\
Washenfelder (2011) & CRDS UV absorption & 93 & 0.026 & 1 & Consumables \\
Zahn (2012) & Chemiluminescence & $\mathrm{n} / \mathrm{a}$ & 10 & 50 & Consumables, rapid dye degradation \\
Darby (2012) & CEAS & 25 & 8 & 0.1 & Stability of UV source \\
\hline
\end{tabular}

Future generations of the IBB-CEAS system will employ tailored filtering to further reject OBL, thereby improving system performance.

Measurement precision is often improved upon with signal averaging. For an ideal system limited by white noise, averaging can improve the signal-to-noise ratio by the square root of the number of averages. However, averaging gains are often limited by systematic sources such as thermal drift that do not benefit from additional averaging. For IBB-CEAS, the precision is dependent on the stability of the DC component of the signal. In this system, it is the combination of stability from cavity coupling, LED output $\left(I_{\text {in }}\right)$, the amplifier, and detector responsivity. Contributions from any of these components to the DC signal cannot be averaged out and dictate the time scale for re-zeroing the measurement system for the condition of zero-ozone $\left(I_{0}\right)$. Figure 6 shows the total system stability $\left(I_{0}\right)$ and the effects of signal averaging. Allan variance analysis on long period, steady-state measurements yields valuable information on practical system limits. Non-stochastic noise is the primary limitation in this system keeping the limit of detection to a few hundred ppt for an averaging time of approximately $30 \mathrm{~s}$, inferred from the minimum in the Allan plot. The system drift also dictates a period of a few hundred seconds for re-determining $I_{\mathrm{O}}$ with a zero-ozone measurement in order to maintain $<1 \mathrm{ppb}$ ozone detection. The increasing variance at short integration time $(t=0.1$ to $0.4 \mathrm{~s})$ is due to the bandwidth limit of the amplifier at high gain $(\mathrm{BW}=10 \mathrm{~Hz})$ and has been previously described (Werle, 2011). A low-noise, fixed-gain amplifier with a higher bandwidth limit such as the Femto LCA-200-10G ( gain $=1 \times 10^{10} \mathrm{~V} / \mathrm{A}, \mathrm{BW}=200 \mathrm{~Hz}$ ), coupled with a higher throughput pump, would allow for $>10 \mathrm{~Hz}$ instrument response and would yield more familiar Allan variance results.

We can estimate the full dynamic range of the IBB-CEAS measurement system by approximating Eq. (3) to account for the OBL reduction of enhancement $(50 \times$ enhancement $\rightarrow$ $R=98 \%$ ). If we define the dynamic range as the noise floor up to an absorbance of 1 , for $0.1 \mathrm{~s}$ measurements, IBB-CEAS has a measurement capability from $1 \mathrm{ppb}$ to $\sim 15 \mathrm{ppm}$. Combining IBB-CEAS with single-pass measurements would extend the upper end measurements to about $730 \mathrm{ppm}$. This parallel measurement would have the added benefit of selfcalibrating the enhancement factor for when IBB-CEAS and single-pass both have appreciable transmission losses.

The present IBB-CEAS system with a base path of $14.5 \mathrm{~cm}$ has a sensitivity of $<1 \mathrm{ppb}$, a dynamic range of $1 \mathrm{ppb}$ to $730 \mathrm{ppm}$ (with tandem single-pass measurement/calibration cell) at an integration time of $0.1 \mathrm{~s}$, and requires no consumables. This very fast response time could be particularly useful for airborne measurements where a significantly improved resolution for ozone mapping could be obtained. As a comparison, we can look at the performance of several ozone instruments shown in Table 1.

\section{Conclusions}

The work presented here demonstrates a compact, selfcalibrating optical instrument for absolute measurements of ozone at $1 \mathrm{ppm}$ sensitivities at $0.1 \mathrm{~s}$ or faster with no consumables. These results are a substantial improvement over related single-pass instrumentation (also operating at $255 \mathrm{~nm}$ ), which typically takes a few seconds to a minute to attain a detection limit of a few ppb. The instrument is capable of sensitive measurements at ozone concentrations relevant to both the troposphere and the stratosphere. It is anticipated that simple improvements limiting the transmission of out of band light will provide further gains in sensitivity. Improving thermal stability of the UV LED source will also minimize the frequency of re-establishing $I_{\mathrm{o}}$.

The high sensitivity and rapid measurement capabilities of the IBB-CEAS ozone monitor have clear applications for airborne platforms. With the ability to measure unique air samples at $10 \mathrm{~Hz}$ with $1 \mathrm{ppb}$ sensitivities, the IBB-CEAS ozone measurement system will allow for one to two orders of magnitude of improvement in spatial measurement resolution for airborne platforms currently using traditional optical instrumentation. 
Acknowledgements. This manuscript has been authored by employees of Southwest Sciences, Inc. under Contract/Grant No NNX12CD23P with the National Aeronautics and Space Administration. The United States Government has a nonexclusive, irrevocable, worldwide license to prepare derivative works, publish or reproduce this manuscript, and allows others to do so, for United States Government purposes. Any publisher accepting this manuscript for publication acknowledges that the United States Government retains such a license in any published form of this manuscript. All other rights are retained by the copyright owner.

Edited by: P. Werle

\section{References}

Ball, S. M., Langridge, J. M., and Jones, R. L.: Broadband cavity enhanced absorption spectroscopy using light emitting diodes, Chem. Phys. Lett., 398, 68-74, doi:10.1016/J.Cplett.2004.08.144, 2004.

Brown, S. S., Dubé, W. P., Karamchandani, P., Yarwood, G., Peischl, J., Ryerson, T. B., Neuman, J. A., Nowak, J. B., Holloway, J. S., Washenfelder, R. A., Brock, C. A., Frost, G. J., Trainer, M., Parrish, D. D., Fehsenfeld, F. C., and Ravishankara, A. R.: Effects of $\mathrm{NO}_{\mathrm{x}}$ control and plume mixing on nighttime chemical processing of plumes from coal-fired power plants, J. Geophys. Res.-Atmos., 117, D07304, doi:10.1029/2011jd016954, 2012.

Busch, K. W., Hennequin, A., and Busch, M. A.: Introduction to Optical Cavities, in: Cavity-Ringdown Spectroscopy, ACS Symposium Series, Am. Chem. Soc., 720, 20-33, 1999.

Cullen, J. and Neale, P.: Ultraviolet radiation, ozone depletion, and marine photosynthesis, Photosynth. Res., 39, 303-320, doi:10.1007/bf00014589, 1994.

Darby, S. B., Smith, P. D., and Venables, D. S.: Cavity-enhanced absorption using an atomic line source: application to deep-UV measurements, Analyst, 137, 2318-2321, 2012.

Fiedler, S. E., Hese, A., and Ruth, A. A.: Incoherent broad-band cavity-enhanced absorption spectroscopy, Chem. Phys. Lett., 371, 284-294, doi:10.1016/S0009-2614(03)00263-X, 2003.

Finlayson-Pitts, B. J. and Pitts, J. N., Jr.: Tropospheric Air Pollution: Ozone, Airborne Toxics, Polycyclic Aromatic Hydrocarbons, and Particles, Science, 276, 1045-1051, doi:10.1126/science.276.5315.1045, 1997.

Fuhrer, J. and Booker, F.: Ecological issues related to ozone: agricultural issues, Environ. Int., 29, 141-154, doi:10.1016/s01604120(02)00157-5, 2003

Gao, R. S., Ballard, J., Watts, L. A., Thornberry, T. D., Ciciora, S. J., McLaughlin, R. J., and Fahey, D. W.: A compact, fast UV photometer for measurement of ozone from research aircraft, Atmos. Meas. Tech., 5, 2201-2210, doi:10.5194/amt-5-2201-2012, 2012.

Gauderman, W. J., Gilliland, G. F., Vora, H., Avol, E., Stram, D., McConnell, R., Thomas, D., Lurmann, F., Margolis, H. G., Rappaport, E. B., Berhane, K., and Peters, J. M.: Association between Air Pollution and Lung Function Growth in Southern California Children: Results from a Second Cohort, Am. J. Respir. Crit. Care Med., 166, 76-84, doi:10.1164/rccm.2111021, 2002.

Gauss, M., Myhre, G., Pitari, G., Prather, M. J., Isaksen, I. S. A., Berntsen, T. K., Brasseur, G. P., Dentener, F. J., Derwent, R. G., Hauglustaine, D. A., Horowitz, L. W., Jacob, D. J., Johnson, M.,
Law, K. S., Mickley, L. J., Müller, J. F., Plantevin, P. H., Pyle, J. A., Rogers, H. L., Stevenson, D. S., Sundet, J. K., van Weele, M., and Wild, O.: Radiative forcing in the 21 st century due to ozone changes in the troposphere and the lower stratosphere, J. Geophys. Res.-Atmos., 108, 4292, doi:10.1029/2002jd002624, 2003.

Gherman, T., Venables, D. S., Vaughan, S., Orphal, J., and Ruth, A. A.: Incoherent broadband cavity-enhanced absorption spectroscopy in the near-ultraviolet: application to $\mathrm{HONO}$ and $\mathrm{NO}_{2}$, Environ. Sci. Technol., 42, 890-895, 2008.

Jones, R. L., Ball, S. M., and Shallcross, D. E.: Small scale structure in the atmosphere: implications for chemical composition and observational methods, Faraday Discuss., 130, 165-179, 2005.

Kalnajs, L. E. and Avallone, L. M.: A Novel Lightweight Low-Power Dual-Beam Ozone Photometer Utilizing SolidState Optoelectronics, J. Atmos. Ocean. Technol., 27, 869-880, doi:10.1175/2009jtecha1362.1, 2009.

Komhyr, W. D.: Electrochemical concentration cells for gas analysis, Ann. Geophys., 25, 203-210, 1969,

http://www.ann-geophys.net/25/203/1969/.

Langridge, J. M., Ball, S. M., and Jones, R. L.: A compact broadband cavity enhanced absorption spectrometer for detection of atmospheric $\mathrm{NO}_{2}$ using light emitting diodes, Analyst, 131, 916 922, doi:10.1039/b605636a, 2006.

Liu, M. and Tian, H.: China's land cover and land use change from 1700 to 2005: Estimations from high-resolution satellite data and historical archives, Global Biogeochem. Cy., 24, GB3003, doi:10.1029/2009gb003687, 2010.

Matross, D. M., Andrews, A., Pathmathevan, M., Gerbig, C., Lin, J. C., Wofsy, S. C., Daube, B. C., Gottlieb, E. W., Chow, V. Y., Lee, J. T., Zhao, C., Bakwin, P. S., Munger, J. W., and Hollinger, D. Y.: Estimating regional carbon exchange in New England and Quebec by combining atmospheric, ground-based and satellite data, Tellus B, 58, 344-358, doi:10.1111/j.1600-0889.2006.00206.x, 2006.

Molina, L. T. and Molina, M. J.: Absolute Absorption Cross Sections of Ozone in the 185- to 350-nm Wavelength Range, J. Geophys. Res., 91, 14501-14508, doi:10.1029/JD091iD13p14501, 1986.

Monks, P. S., Granier, C., Fuzzi, S., Stohl, A., Williams, M. L., Akimoto, H., Amann, M., Baklanov, A., Baltensperger, U., Bey, I., Blake, N., Blake, R. S., Carslaw, K., Cooper, O. R., Dentener, F., Fowler, D., Fragkou, E., Frost, G. J., Generoso, S., Ginoux, P., Grewe, V., Guenther, A., Hansson, H. C., Henne, S., Hjorth, J., Hofzumahaus, A., Huntrieser, H., Isaksen, I. S. A., Jenkin, M. E., Kaiser, J., Kanakidou, M., Klimont, Z., Kulmala, M., Laj, P., Lawrence, M. G., Lee, J. D., Liousse, C., Maione, M., McFiggans, G., Metzger, A., Mieville, A., Moussiopoulos, N., Orlando, J. J., O’Dowd, C. D., Palmer, P. I., Parrish, D. D., Petzold, A., Platt, U., Pöschl, U., Prévôt, A. S. H., Reeves, C. E., Reimann, S., Rudich, Y., Sellegri, K., Steinbrecher, R., Simpson, D., ten Brink, H., Theloke, J., van der Werf, G. R., Vautard, R., Vestreng, V., Vlachokostas, C., and von Glasow, R.: Atmospheric composition change - global and regional air quality, Atmos. Environ., 43, 5268-5350, doi:10.1016/j.atmosenv.2009.08.021, 2009.

Proffitt, M. H. and McLaughlin, R. J.: Fast-response dualbeam UV-absorption ozone photometer suitable for use on stratospheric balloons, Rev. Sci. Instrum., 54, 1719-1728, doi:10.1063/1.1137316, 1983. 
Ridley, B. A., Grahek, F. E., and Walega, J. G.: A Small High-Sensitivity, Medium-Response Ozone Detector Suitable for Measurements from Light Aircraft, J. Atmos. Ocean. Technol., 9, 142-148, doi:10.1175/15200426(1992)009<0142:ashsmr>2.0.co;2, 1992.

Sillman, S.: The relation between ozone, $\mathrm{NO}_{\mathrm{x}}$ and hydrocarbons in urban and polluted rural environments, Atmos. Environ., 33, 1821-1845, doi:10.1016/s1352-2310(98)00345-8, 1999.

Taghavi, M., Cautenet, S., and Arteta, J.: Impact of a highly detailed emission inventory on modeling accuracy, Atmos. Res., 74, 6588, doi:10.1016/j.atmosres.2004.06.007, 2005.

Venables, D. S., Staak, M., and Ruth, A. A.: Broadband cavityenhanced absorption spectroscopy for trace gas detection, Opto-Ireland 2005, Opt. Sens. Spectrosc., 5826, 202-211, doi:10.1117/12.605111, 2005.

Viallon, J., Moussay, P., Norris, J. E., Guenther, F. R., and Wielgosz, R. I.: A study of systematic biases and measurement uncertainties in ozone mole fraction measurements with the NIST Standard Reference Photometer, Metrologia, 43, 441-450, 2006.
Washenfelder, R. A., Wagner, N. L., Dube, W. P., and Brown, S. S.: Measurement of Atmospheric Ozone by Cavity Ringdown Spectroscopy, Environ. Sci. Technol., 45, 2938-2944, doi:10.1021/es103340u, 2011.

Werle, P.: Accuracy and precision of laser spectrometers for trace gas sensing in the presence of optical fringes and atmospheric turbulence, Appl. Phys. B, 102, 313-329, doi:10.1007/s00340010-4165-9, 2011.

Wu, T., Zhao, W. X., Li, J. S., Zhang, W. J., Chen, W. D., and Gao, X. M.: Incoherent Broadband Cavity Enhanced Absorption Spectroscopy Based on LED, Spectrosc. Spect. Anal., 28, 2469-2472, 2008.

Zahn, A., Weppner, J., Widmann, H., Schlote-Holubek, K., Burger, B., Kühner, T., and Franke, H.: A fast and precise chemiluminescence ozone detector for eddy flux and airborne application, Atmos. Meas. Tech., 5, 363-375, doi:10.5194/amt-5-363-2012, 2012.

Zucco, M., Curci, S., Castrofino, G., and Sassi, M. P.: A comprehensive analysis of the uncertainty of a commercial ozone photometer, Meas. Sci. Technol., 14, 1683-1689, 2003. 